5 Pollock JE, Neal JM, Stephenson CA, Wiley CE.

Prospective study of the incidence of transient radicular irritation in patients undergoing spinal anesthesia.

Anesthesiology 1996; 84: 1361-7.

\section{Anesthesia for magnetic resonance imaging in children: a survey of Canadian pediatric centres}

To the Editor:

We recently conducted a telephone survey of pediatric anesthesia departments in 11 Canadian university centres. Department chiefs (or designates) were asked to identify current anesthesia practice and concerns for pediatric magnetic resonance imaging (MRI). In all 11 centres, care was provided by pediatric anesthesiologists, with ten centres having MRI compatible machines available. All centres routinely used capnography and pulse oximetry. Eight centres routinely used non-invasive blood pressure monitoring. Five centres routinely used electrocardiogram (ECG) monitoring, and two centres had no MRI compatible ECG available. In seven centres the anesthesiologists were located in the control room during scanning. Staff were more likely to remain in the scanning room if a slave monitor was unavailable in the control room.

Six centres predominantly used a propofol total iv anesthesia technique (TIVA), with the other five centres using a volatile technique more frequently or exclusively. Centres predominantly using TIVA were less likely to instrument the airway (Table). Propofol induction and maintenance dose estimates ranged from 2 to $6 \mathrm{mg} \cdot \mathrm{kg}^{-1}$ (mean 3.7) and 100 to $250 \mu \mathrm{g} \cdot \mathrm{kg}^{-1} \cdot \mathrm{min}^{-1}$ (mean 165) respectively, with one centre using boluses as required rather than an infusion. Three centres routinely using TIVA had no MRI compatible infusion pump available;

TABLE Comparison of centres using TIVA as predominant technique $v s$ centres occasionally using TIVA

\begin{tabular}{lll}
\hline & $\begin{array}{l}\text { Centres predominantly } \\
\text { using TIVA } \\
(n=6)\end{array}$ & $\begin{array}{l}\text { Centres occasionally } \\
\text { using TIVA } \\
(n=4)\end{array}$ \\
\hline $\begin{array}{l}\text { Routine airway } \\
\text { Nasal prongs }\end{array}$ & 4 & \\
Mask & 1 & 0 \\
LMA & 0 & 0 \\
Mixture (LMA, ETT & 3 \\
or no airway) & 1 & 1 \\
\hline
\end{tabular}

TIVA $=$ total $i v$ anesthesia; LMA = laryngeal mask airway; ETT = endotracheal tube. instead using a remote pump with a hydraulic interface, or a manual method calculating drops per minute. Propofol sedation techniques have been well described previously, although often with lower doses of propofol than we found in this survey. ${ }^{1-3}$ Centres not routinely using TIVA had concerns about maintaining and monitoring the airway if nasal prongs or a face mask were used.

Annual caseload estimates ranged from 20 to 1,400 children. Many centres noted increasing demand from radiology departments for anesthesia services, with one centre commenting that anesthesia out of the operating room currently accounts for greater than $30 \%$ of the department workload. Most centres felt that seven to eight years was the age at which children more reliably tolerated scanning without anesthesia. The mean daily caseload for centres predominantly using TIVA was $9.2(5-12)$ vs $7.2(5-10)$ for other centres, possibly due to shorter induction and emergence periods as the airway is instrumented less often.

We conclude that anesthesia for MRI accounts for a significant workload for pediatric anesthesiologists. Some centres remain concerned about the safety of TIVA using nasal prongs or face mask despite the suggestion it may decrease anesthesia time.

\section{Andrew Usher $\mathrm{MB}$ CHB}

Ramona Kearney MD FRCPC

Edmonton, Alberta

\section{References}

I Vangerven M, Van Hemelrijck J, Wouters $P$, Vandermeersch E, Van Aken H. Light anaesthesia with propofol for paediatric MRI. Anaesthesia 1992; 47: 706-7.

2 Bloomfield EL, Masaryk TJ, Caplin A, et al. Intravenous sedation for MR imaging of the brain and spine in children: pentobarbital versus propofol. Radiology 1993; 186: 93-7.

3 Lefever EB, Potter PS, Seeley NR. Propofol sedation for pediatric MRI (Letter). Anesth Analg 1993; 76: 919-20.

\section{Lafutidine vs cimetidine to decrease gastric fluid acidity and volume in children}

To the Editor:

General anesthesia carries a risk for aspiration pneumonitis. ${ }^{1}$ Histamine $\mathrm{H}_{2}$ receptor antagonists have been administered to minimize the risk of acid aspiration syndrome by decreasing gastric secretion. ${ }^{2}$ In the 